\title{
Trichloroacetic acid fueled practical amine purifications
}

\author{
Aleena Thomas, Baptiste Gasch, Enzo Olivieri and Adrien Quintard ${ }^{*}$
}

\author{
Full Research Paper \\ Address: \\ Aix-Marseille Univ, CNRS, Centrale Marseille, iSm2, Marseille, France \\ Email: \\ Adrien Quintard* - adrien.quintard@univ-amu.fr \\ * Corresponding author \\ Keywords: \\ amines; decarboxylation; eco-compatible; out of equilibrium; \\ purification
}

Open Access

\author{
Beilstein J. Org. Chem. 2022, 18, 225-231. \\ https://doi.org/10.3762/bjoc.18.26 \\ Received: 14 December 2021 \\ Accepted: 17 February 2022 \\ Published: 24 February 2022 \\ Associate Editor: L. Vaccaro \\ (C) 2022 Thomas et al.; licensee Beilstein-Institut. \\ License and terms: see end of document.
}

\begin{abstract}
Amine purification have for long been dominated by tedious stepwise processes involving the generation of large amounts of undesired waste. Inspired by recent work on out of equilibrium molecular machinery, using trichloroacetic acid (TCA), we disclose a purification technique considerably decreasing the number of operations and the waste generation required for such purifications. At first, TCA triggers the precipitation of the amines through their protonated salt formation, enabling the separation with the impurities. From these amine salts, simple decarboxylation of TCA liberates volatile $\mathrm{CO}_{2}$ and chloroform affording directly the pure amines. Through this approach, a broad range of diversely substituted amines could be isolated with success.
\end{abstract}

\section{Introduction}

Isolation of pure amines from reaction mixtures or natural extracts is crucial in modern organic chemistry. However, the most widely applied methods for these purifications have remained unchanged for decades. Aside from distillation or lengthy and costly chromatography techniques generating large amounts of waste, classical purification of amines found in practical textbooks [1-3] imply the temporary formation of a salt in the presence of an acid (Scheme 1). This strategy has been applied since the beginning of the 19th century as highlighted by the Sertürner isolation of morphine [4]. However, after formation of the amine acid (ammonium) salt and separation of the impurities, another separation is required to liberate again the free amine resulting in the undesired generation of waste. Most notably, this step can go through a liquid-liquid separation that requires multiple operations generating large amounts of waste notably arising from the different organic and aqueous layers.

In the context of the development of more eco-compatible organic synthesis limiting the number of operations and the associated generation of waste, discovery of alternative purification techniques is mandatory.

Avoiding waste accumulation, dissipative acids have recently found interesting applications in the field of out of equilibrium molecular switches and motors [5]. They enable the temporary formation of protonated amines which evolve spontaneously over time back again to the neutral amine upon release of $\mathrm{CO}_{2}$ 


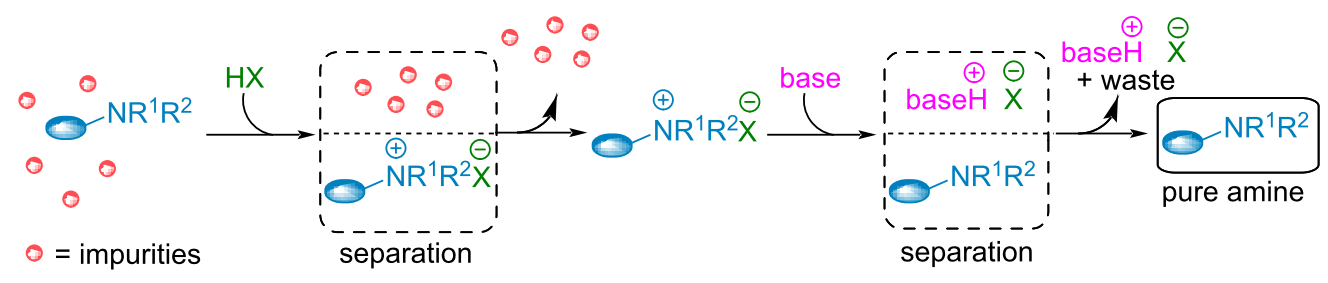

Scheme 1: Classical amine purification.

from the initial acid. Among the potential acids available for such processes, trichloroacetic acid (TCA) has been used to fuel different supramolecular switches [6-10]. This cheap and simple acid enables a temporary protonation while time-controlled decarboxylation liberates volatile $\mathrm{CO}_{2}$ and chloroform as single waste (Scheme 2a). This strategy has been applied with success by the groups of Takata, Leigh, Kim and ours to time control different molecular switches ranging from rotaxanes, cucurbit[8]uril, to supramolecular smart materials [11-16]. TCA is also known for its application in the precipitation of proteins through what is believed to be an unfolding of the proteins structures $[17,18]$.

In this context, we hypothesized that TCA could be used to facilitate amines purification considerably limiting waste generation and operations, which is to the best of our knowledge unprecedented (Scheme 2b). Addition of this acid to amines containing impurities could trigger the generation of a precipitating salt, enabling the separation from the impurities. From there, simple decarboxylation, spontaneous or catalyzed through the addition of a small amount of low boiling organic bases, would liberate the volatile wastes and the clean pure amine. Herein, we present our success in developing such a technique.

\section{Results and Discussion}

In order to prove the feasibility of a TCA-induced amine purification, we first focused on the study of the different parameters crucial for such a process. For such purpose, we initially studied the purification of a model 1:1 mixture of dicyclohexylamine and naphthalene (Table 1). Gratifyingly, adding 3 equivalents of TCA to this mixture dissolved in EtOAc, precipitation of the amine salt enabled the removal of naphthalene in the solvent.

a) TCA as fuel for molecular switches:

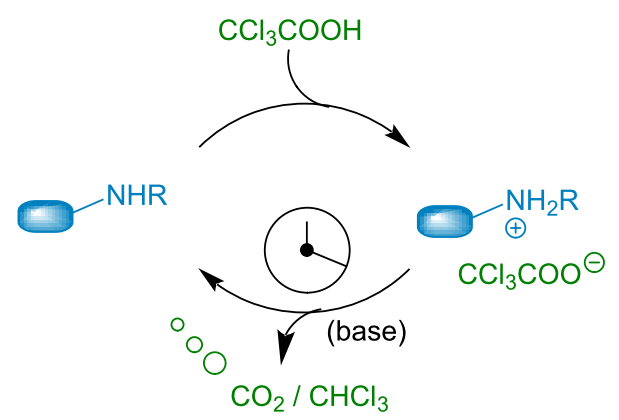

b) TCA as a fuel for amine purification:

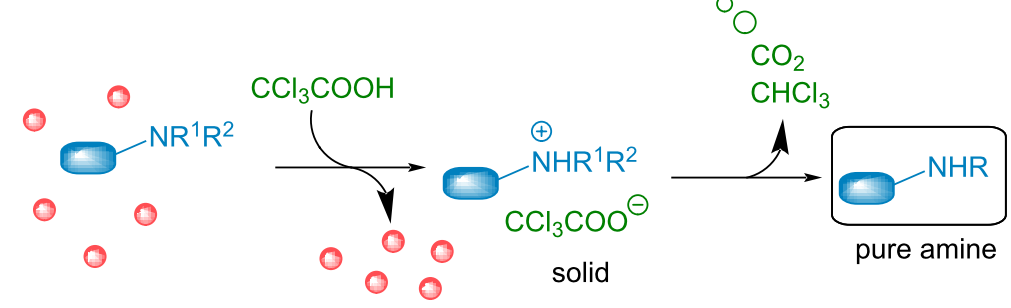

= impurities 
Table 1: Optimization of the decarboxylation.

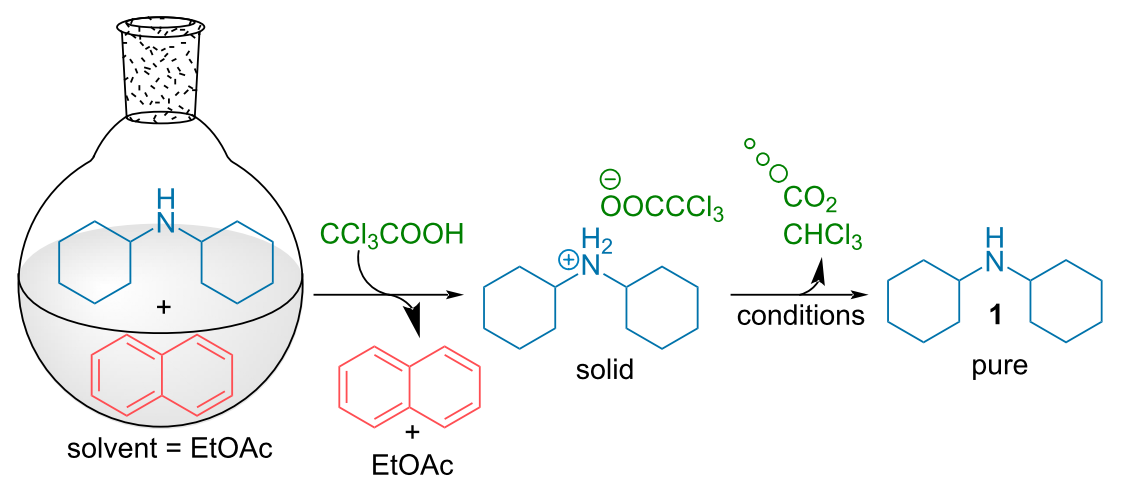

\begin{tabular}{lll}
\hline Entry & Decarboxylation conditions & Result \\
\hline 1 & EtOAc, $60^{\circ} \mathrm{C}, 24 \mathrm{~h}$ & partial TCA decarboxylation \\
2 & neat, $100{ }^{\circ} \mathrm{C}, 1 \mathrm{~h}$ & partial TCA decarboxylation \\
3 & $\mathrm{DMF}, 60^{\circ} \mathrm{C}, 15 \mathrm{~min}$ & complete TCA decarboxylation but difficulty in removing DMF \\
$\mathbf{4}$ & $\mathbf{C H}_{\mathbf{3}} \mathbf{C N}, \mathbf{r t}, \mathbf{2 4} \mathbf{~ h}$ & complete TCA decarboxylation (86\% purification yield) \\
$\mathbf{5}$ & $\mathbf{C H}_{\mathbf{3}} \mathbf{C N}, \mathbf{E t} \mathbf{3} \mathbf{N}\left(\mathbf{1 . 5}\right.$ equiv), $\mathbf{6 0}{ }^{\circ} \mathbf{C}, \mathbf{1 5} \mathbf{~ m i n , ~ v a c u u m ~}{ }^{\mathrm{a}}$ & complete TCA decarboxylation (94\% purification yield) \\
\hline
\end{tabular}

$\mathrm{a}_{15}$ minutes heating performed in a rotary evaporator with a gradual decrease of the pressure from 100 to 10 mbar (see Supporting Information File 1).

Beside the choice of the solvent for the crystallization which strongly depends on the solubility of the protonated amine salts involved, we first focused on the optimization of the decarboxylation conditions (Table 1, see Supporting Information File 1 for additional optimization). From the solid amine salt, different conditions were thus tested for a rapid decarboxylation. When stirring the amine salt in EtOAc, only a partial decarboxylation was observed even after 24 hours (Table 1, entry 1). Presence of TCA in the ${ }^{1} \mathrm{H}$ NMR spectra is easily monitored through a broad peak around $9 \mathrm{ppm}$ and also through the upfield migration of the other peaks of the amine ammonium salt. Heating the amine salt precipitate neat at $100{ }^{\circ} \mathrm{C}$ also provided partial decarboxylation (Table 1, entry 2). In sharp contrast, use of Lewis basic solvents such as DMF considerably accelerate the decarboxylation kinetic (Table 1, entry 3 ) with the recovery of the free amine after 24 hours. However, this solvent is not convenient given its high boiling point making difficult it's separation from the purified amine. Accordingly, use of acetonitrile (Table 1, entry 4), also provides the free amine easily. Moreover, the solvent is easily evaporated concomitantly with the removal of the generated $\mathrm{CO}_{2}$ and chloroform, providing the isolated pure amine in $86 \%$ purification yield. This system is closely related to out of equilibrium supramolecular machinery through a temporary protonation returning to the initial state upon time [3-5]. While conceptually interesting, in terms of laboratory practicability, it would be desirable to have a faster release of the free amine. For this purpose, a small amount of volatile base $\left(\mathrm{Et}_{3} \mathrm{~N}\right)$ was incorporated to catalyze the TCA decarboxylation while heating at $60{ }^{\circ} \mathrm{C}$ in a rotary evaporator under reduced pressure. Through this technique, the pure free amine could be isolated after 15 minutes of gentle heating, simultaneously evaporating the generated chloroform as well as $\mathrm{CH}_{3} \mathrm{CN}$ and $\mathrm{Et}_{3} \mathrm{~N}$ (Table 1, entry 5). Overall, the TCA-induced purification protocol enables the convenient purification of the initial mixture with the isolation of pure dicyclohexylamine in an $94 \%$ yield. The excellent yield observed for the purification technique of this, high boiling amine, demonstrates all the potential of this system.

In order to highlight the interest of this technique and its broad applicability, dicyclohexylamine could be purified from various mixtures containing 1 equivalent of structurally different impurities (Table 2). Aside from naphthalene (Table 2, entry 1), dicyclohexylamine could be isolated in its pure form starting from model mixtures containing various aromatics, phenols, alkanes or alkenes in overall purification yields ranging from 53 to $98 \%$. The lower yields are observed for coordinating phenol and catechol (Table 2, entries 3 and 4), probably impacting the crystallization process, while less coordinating species all provided purification yields above $80 \%$. Finally, polar DMF was removed from dicyclohexylamine in $81 \%$ yield (Table 2, entry 8 ).

Aside from the potential impurities, we also focused on the purification of other types of amines (Table 3). One equivalent 
Table 2: Examples of impurities removed from dicyclohexylamine.

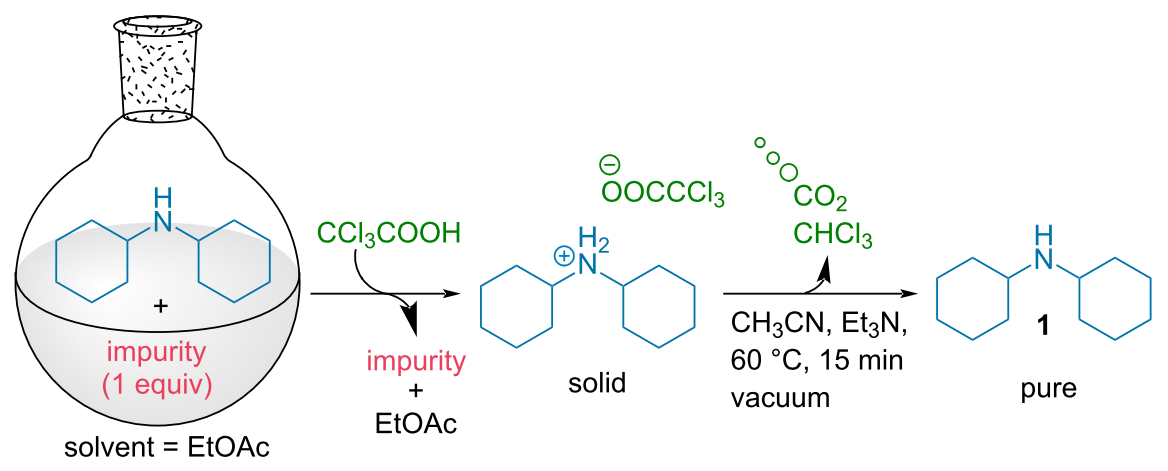

\begin{tabular}{|c|c|c|}
\hline Entry & Impurity (1 equiv) & Purification yield \\
\hline 1 & & $94 \%$ \\
\hline 2 & & $95 \%$ \\
\hline 3 & & $53 \%$ \\
\hline 4 & & $69 \%$ \\
\hline 5 & & $80 \%$ \\
\hline 6 & & $90 \%$ \\
\hline 7 & & $98 \%$ \\
\hline 8 & & $81 \%$ \\
\hline
\end{tabular}

aContains $2 \%$ of catechol.

of naphthalene or 2-methoxynaphthalene were chosen as representative model impurities given their potential $\pi$-stacking ability and solid state at room temperature. Consequently, they are more challenging to separate from the generated amine salts, demonstrating the power of the method. Aside from secondary dicyclohexylamine (Table 3, entry 1 ), a broad range of primary amines could also be separated from the aromatic impurities (Table 3, entries 2-10). As for other purification techniques, the challenge lies in the identification of the appropriate solvent to dissolve well the initial mixture and induce the amine-TCA complex precipitation. For such purpose, EtOAc, pentane, $\mathrm{CH}_{3} \mathrm{CN}$ or $\mathrm{Et}_{2} \mathrm{O}$ have been used in this table depending on the solubility observed (see Supporting Information File 1 for details). Depending on the TCA-amine salt solubility in the solvent used, the purified primary amines could be isolated in 40-94\% yield. Bulky 2,2,6,6-tetramethyl-4-piperidone could also be isolated from naphthalene in $94 \%$ yield through this approach (Table 3, entry 11). Other heterocyclic amines such as acridine or 1,2-dimethylimidazole could also be isolated with success in 53-65\% yields (Table 3, entries 12 and 13). Of importance, this technique is also efficient for the isolation of highly complex natural amines such as brucin, isolated in 57\% yield using TCA (Table 3, entry 14).

As mentioned, identification of a suitable solvent solubilizing the initial mixture and enabling precipitation/crystallization of 
Table 3: Scope of purified amines.
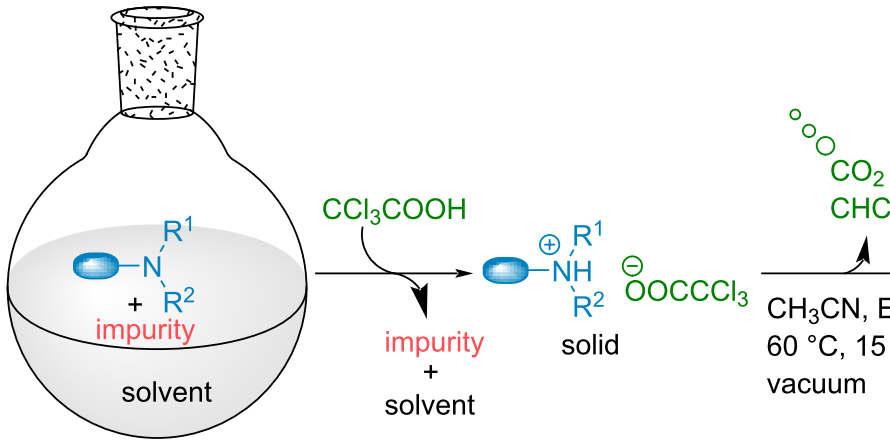

$\mathrm{CO}_{2}$

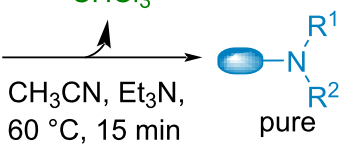

vacuum

\begin{tabular}{|c|c|c|c|}
\hline Entry $^{\mathrm{a}}$ & Amine/impurity (1:1 ratio) & Precipitation solvent & Amine purification yield \\
\hline 1 & & EtOAc & $94 \%$ \\
\hline 2 & & EtOAc & $72 \%$ \\
\hline 3 & & EtOAc & $40 \%$ \\
\hline 4 & & EtOAc & $40 \%$ \\
\hline 5 & & EtOAc & $71 \%$ \\
\hline 6 & & EtOAc & $79 \%$ \\
\hline 7 & & pentane & $45 \%$ \\
\hline 8 & & pentane & $81 \%$ \\
\hline 9 & & EtOAc & $91 \%$ \\
\hline
\end{tabular}


Table 3: Scope of purified amines. (continued)

10<smiles>CC(=O)c1ccncc1N</smiles>

11

12<smiles>COc1ccc2ccccc2c1</smiles>

12

13

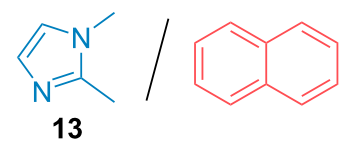

13

14<smiles>CC1(C)CC(=O)CC(C)(C)N1</smiles>

EtOAc

pentane- $\mathrm{Et}_{2} \mathrm{O}$

pentane

$\mathrm{CH}_{3} \mathrm{CN}$
$53 \%$

$72 \%$

$94 \%$

$65 \%$

$57 \%$ the amine salt is the key for success in this method. As a consequence, for now, we also experienced absence of amine salt precipitation using different other amines (see Supporting Information File 1 for details). However, we are convinced that simple solvent screening could unlock the purification of these other amines also enabling an increase in the purification yields.

Finally, in order to demonstrate the potential of the purification technique, we performed the reduction of 4-nitrotoluene and directly purified the crude mixture through the TCA purification protocol to obtain pure $p$-toluidine in $66 \%$ isolated yield (Scheme 3). This highlights the potential of this technique for organic synthesis.

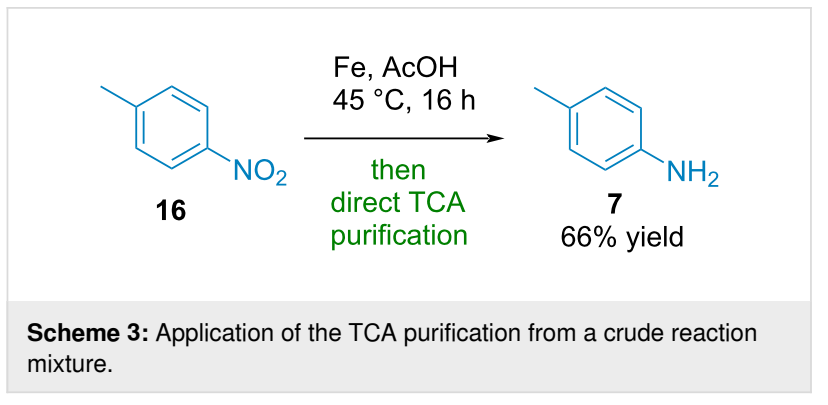

\section{Conclusion}

To conclude, we have disclosed a new approach considerably limiting waste and operations necessary for amine purification. Taking advantage of a temporary protonation with TCA, the solid amine salts generated can be separated from the impurities. Closely related to out of equilibrium systems applied in molecular switches and motors under temporal control, from the amine salt, isolation of the pure free amine occurs through a simple decarboxylation of TCA, releasing volatile $\mathrm{CO}_{2}$ and $\mathrm{CHCl}_{3}$. As a result, purification of these amines can proceed easily and with excellent yields (up to $98 \%$ overall purification yield). This method can virtually be applied for any amine purification given that an appropriate solvent is identified for the precipitation of the TCA-amine salt. Given the decrease in required operations and waste generation, this methodology should rapidly find applications in organic chemistry laboratories but also possibly on industrial scale.

\section{Experimental}

Typical experimental procedure with dicyclohexylamine 1: Dicyclohexylamine $(37 \mathrm{mg}, 0.21 \mathrm{mmol}, 1$ equiv) and 2-methoxynaphthalene (33 mg, $0.21 \mathrm{mmol}, 1$ equiv) were dissolved in EtOAc ( $1 \mathrm{~mL})$. TCA (100 mg, $0.62 \mathrm{mmol}, 3$ equiv) 
was then added at room temperature. The white precipitate formed was filtered and washed with EtOAc $(2 \times 2 \mathrm{~mL})$. $\mathrm{CH}_{3} \mathrm{CN}(2 \mathrm{~mL})$ and $\mathrm{Et}_{3} \mathrm{~N}(0.04 \mathrm{~mL}, 0.32 \mathrm{mmol}, 1.5$ equiv) were then added and the solvent was evaporated at $60{ }^{\circ} \mathrm{C}$ for $15 \mathrm{~min}$ (100 to $10 \mathrm{mbar}$ ). The purified amine ( $35 \mathrm{mg}, 0.2 \mathrm{mmol}, 95 \%$ yield) was obtained as a colorless liquid. ${ }^{\mathbf{1}} \mathrm{H}$ NMR $(400 \mathrm{MHz}$, $\left.\mathrm{CDCl}_{3}\right) \delta$ 2.56-2.49 (m, 2H), 1.85-1.80 (m, 4H), 1.72-1.66 (m, $4 \mathrm{H}), 1.60-1.54$ (m, 2H), 1.27-0.94 (m, 10H) ppm.

\section{Supporting Information}

\section{Supporting Information File 1}

Experimental details.

[https://www.beilstein-journals.org/bjoc/content/

supplementary/1860-5397-18-26-S1.pdf]

\section{Acknowledgements}

All technical staff, from Aix-Marseille Spectropole are acknowledged for their support.

\section{Funding}

The project leading to this publication has received funding from the Excellence Initiative of Aix-Marseille University A*Midex, a French "Investissements d'Avenir" programme" (A-M-AAP-EI-17-06-170223-13.06-QUINTARD-SAT). The Centre National de la Recherche Scientifique (CNRS) and AixMarseille Université are warmly acknowledged for financial support.

\section{ORCID ${ }^{\circledR}$ iDs}

Enzo Olivieri - https://orcid.org/0000-0002-9968-2245

Adrien Quintard - https://orcid.org/0000-0003-0193-6524

\section{References}

1. Furniss, B. S.; Hannaford, A. J.; Smith, P. W. G.; Tatchell, A. R. Vogel's, Textbook of Practical Organic Chemistry, 5th ed.; John Wiley \& Sons: Hoboken, NJ, USA, 1991.

2. Zubrick, J. W. The Organic Chem Lab Survival Manual: A Student's Guide to Techniques, 8th ed.; John Wiley \& Sons: Hoboken, NJ, USA, 2012.

3. https://www.masterorganicchemistry.com/2016/08/12/natural-product-is olation-2-purification-of-crude-mixtures-overview/ (accessed Feb 14, 2022).

4. Sertürner, F. W. Ann. Phys. (Berlin, Ger.) 1817, 55, 56-89.

5. Biagini, C.; Di Stefano, S. Angew. Chem., Int. Ed. 2020, 59, 8344-8354. doi:10.1002/anie.201912659

6. Berrocal, J. A.; Biagini, C.; Mandolini, L.; Di Stefano, S. Angew. Chem., Int. Ed. 2016, 55, 6997-7001. doi:10.1002/anie.201602594

7. Ghosh, A.; Paul, I.; Adlung, M.; Wickleder, C.; Schmittel, M. Org. Lett. 2018, 20, 1046-1049. doi:10.1021/acs.orglett.7b03996
8. Del Giudice, D.; Spatola, E.; Cacciapaglia, R.; Casnati, A.; Baldini, L.; Ercolani, G.; Di Stefano, S. Chem. - Eur. J. 2020, 26, 14954-14962. doi:10.1002/chem.202002574

9. Giudice, D. C.; Spatola, E.; Valentini, M.; Bombelli, C.; Ercolani, G.; Di Stefano, S. Chem. Sci. 2021, 12, 7460-7466. doi:10.1039/d1sc01196k

10. Ghosh, A.; Paul, I.; Schmittel, M. J. Am. Chem. Soc. 2021, 143, 5319-5323. doi:10.1021/jacs.1c01948

11. Abe, Y.; Okamura, H.; Nakazono, K.; Koyama, Y.; Uchida, S.; Takata, T. Org. Lett. 2012, 14, 4122-4125. doi:10.1021/ol301771w

12. Zhu, N.; Nakazono, K.; Takata, T. Chem. Lett. 2016, 45, 445-447. doi:10.1246/cl.151190

13. Erbas-Cakmak, S.; Fielden, S. D. P.; Karaca, U.; Leigh, D. A.; McTernan, C. T.; Tetlow, D. J.; Wilson, M. R. Science 2017, 358, 340-343. doi:10.1126/science.aao1377

14. Biagini, C.; Fielden, S. D. P.; Leigh, D. A.; Schaufelberger, F.; Di Stefano, S.; Thomas, D. Angew. Chem., Int. Ed. 2019, 58, 9876-9880. doi:10.1002/anie.201905250

15. Choi, S.; Mukhopadhyay, R. D.; Kim, Y.; Hwang, I.-C.; Hwang, W.; Ghosh, S. K.; Baek, K.; Kim, K. Angew. Chem., Int. Ed. 2019, 58, 16850-16853. doi:10.1002/anie.201910161

16. Olivieri, E.; Quintard, G.; Naubron, J.-V.; Quintard, A. J. Am. Chem. Soc. 2021, 143, 12650-12657. doi:10.1021/jacs.1c05183

17. Sivaraman, T.; Kumar, T. K. S.; Jayaraman, G.; Yu, C. J. Protein Chem. 1997, 16, 291-297. doi:10.1023/a:1026357009886

18. Rajalingam, D.; Loftis, C.; Xu, J. J.; Kumar, T. K. S. Protein Sci. 2009, 18, 980-993. doi:10.1002/pro.108

\section{License and Terms}

This is an open access article licensed under the terms of the Beilstein-Institut Open Access License Agreement (https://www.beilstein-journals.org/bjoc/terms), which is identical to the Creative Commons Attribution 4.0 International License (https://creativecommons.org/licenses/by/4.0). The reuse of material under this license requires that the author(s), source and license are credited. Third-party material in this article could be subject to other licenses (typically indicated in the credit line), and in this case, users are required to obtain permission from the license holder to reuse the material.

The definitive version of this article is the electronic one which can be found at: https://doi.org/10.3762/bjoc.18.26 